\title{
Some features of acoustic and electric responses of near- surface sedimentary rocks during deformations by seismic waves from strong earthquakes $\left(M_{w}>6.5\right)$
}

\author{
Mikhail Mishchenko ${ }^{1, *}$, Oleg Rulenko ${ }^{2}$, and Yuriy Marapulets ${ }^{1}$ \\ ${ }^{1}$ Institute of Cosmophysical Research and Radio Wave Propagation FEB RAS, Mirnaya, 7, Paratunka, \\ Kamchatkskiy kray, 684034, Russia \\ ${ }^{2}$ Institute of Volcanology and Seismology FEB RAS, bul'var Piypa, 9, Petropavlovsk-Kamchatskiy, \\ 683006, Russia
}

\begin{abstract}
Acoustic and electric responses of near-surface sedimentary rocks are considered. They were recorded during the deformations by seismic waves from six earthquakes with magnitude $M_{w}=6.6-7.7$ at the distances of 131-728 $\mathrm{km}$ from epicenters in Kamchatka region. Behavior of both responses during soil displacement and displacement velocity during wave propagation are under the analysis. The dependence of intensity and character of the responses manifestation on earthquake magnitude and the distance to its source had been discovered by the authors earlier and is confirmed in the work. It was discovered that the occurrence of acoustic response in kilohertz range correlates well with the behavior of soil displacement velocity vector and its spectrum.
\end{abstract}

\section{Introduction}

Tectonic process is continuous in seismically active regions. It causes changes in stress-strain state of the earth crust rocks including near-surface ones. Such changes occur at deformation background regime and during preparation of earthquakes which are a seismic component of tectono-seismic process as the result of more intensive deformation of rocks under tectonic forces [1].

When recording geophysical fields at observation sites, one usually deals with nearsurface sedimentary rocks as about $80 \%$ of continent surface is covered by them [2]. They have polydisperse water- and gas-saturated porous structure and are easily deformed due to the fragmental structure. Stress-strain state changes of these rocks are accompanied by anomalous disturbances of near-surface fields. To investigate the mechanisms of formation of such disturbances and possible application as indicators of tectono-seismic process, it is topical to study the responses of these fields on near-surface sedimentary rock deformation. In order to observe a significant effect and correspondence of the results to real deformation process, it is reasonable to carry out the investigations during rock intensive deformations, not in laboratory experiments, but under conditions of natural occurrence.

Rock intensive deformation is observed during propagaton of seismic waves from earthquakes and is accompanied by the transformation of mechanic energy of these waves into the

\footnotetext{
*e-mail: micle@ikir.ru
} 
energies of different physical fields. Such a deformation was used in [3, 4] to detect and to investigate jointly seismoelectric and seismoacoustic responses of near-surface sedimentary rocks. These responses occur as the result of reaction of the whole set of rock fragments, densely packed and having a wide range of sizes, which are located in the vicinity of an observation site. The electric and acoustic signals, recorded during longitudinal and transversal wave propagation, were analyzed in different frequency ranges and their spectrograms were estimated. These papers did not consider seismically-induced displacement and displacement velocity of sedimentary rock near-surface layer.

In the paper we compare for the first time the occurrence of acoustic and electric responses of near-surface sedimentary rocks with the behavior of soil displacement and displacement velocity. Propagations of longitudinal and transversal waves from six strong $\left(M_{w}>6.5\right)$ earthquakes of Kamchatka region at the distances of 131-728 km from epicenters are considered. The obtained results are important for the investigation of mechanic and electrophysical properties of near-surface sedimentary rocks and acoustic and electric signals occurring during their deformations.

\section{Investigation method}

Just like in the papers [3, 4], geo-acoustic and geo-electric observations were carried out at "Karymshina" site $\left(52.83^{\circ} \mathrm{N}, 158.13^{\circ} \mathrm{E}\right)$ IKIR FEB RAS, located in Verkhne-Paratunskaya geothermal system of South Kamchatka (Fig. 1). Observation method and our understanding of generation sources of seismoacoustic and seismoelectric signasl in sedimentary rocks are described in those papers. It is mentioned that based on the results of drilling, near-surface rocks in the region of this site are sedimentary, and the layer thickness is about $50 \mathrm{~m}$.

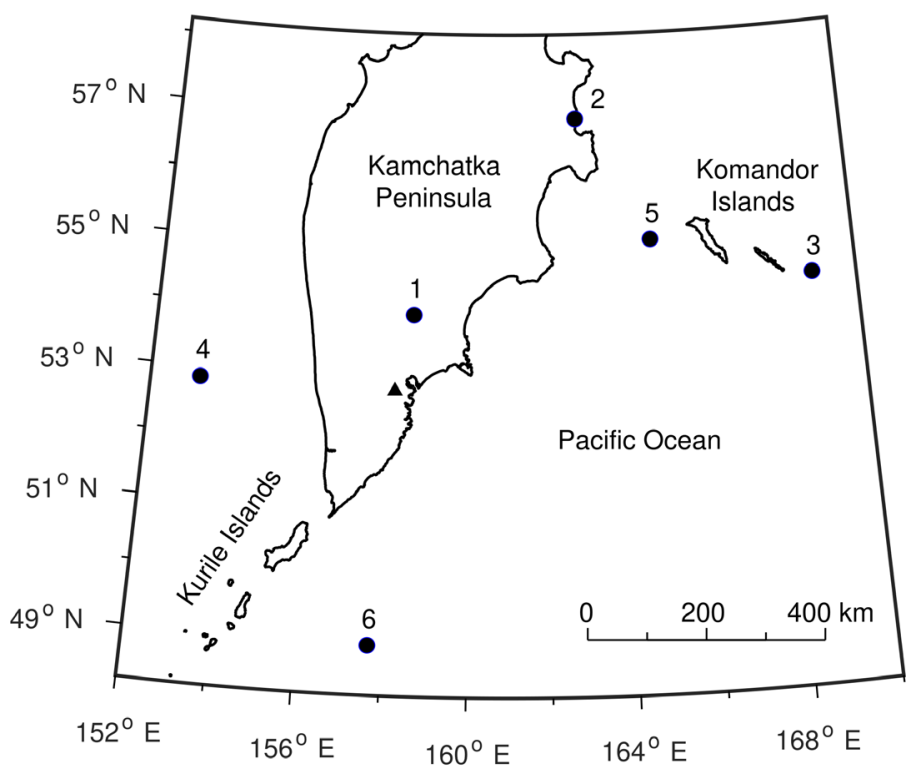

Figure 1. Location of "Karymshina" site ( $\mathbf{\Lambda})$ and of earthquake epicenters (•), for which seismoacoustic and seismoelectric signals were analyzed. Earthquake parameters and their numbers are in the table 1. 
In this work, a new approach in the investigation method is application of record fragments from a three-component broad-band velocigraph installed at seismic "Karymshina" site of Kamchatka Branch of Federal Research Center, Geophysical Survey, Russian Academy of Sciences, $250 \mathrm{~km}$ from our observation point. Three components of soil displacement and displacement velocity were considered on the time interval from two minutes to the time of longitudinal $P$-wave arrival and ten minutes after it. The features of sedimentary rock acoustic and electric response manifestations were compared with the behavior of module of these parameters during seismic wave propagation. As it was noticed in [4], for a hydrophone, installed in a reservoir filled with water, the P-wave is recorded without significant distortions as long as in small volumes $\left(1 \times 1 \times 1 \mathrm{~m}^{3}\right)$ refraction may be neglected. Water does not have form elasticity and the transversal $S$-wave does not propagate in a water basin but, causing horizontal and vertical displacements of soil, it affects hydrophone suspension and manifests in acoustic data. Thus we consider acoustic signals occurring only during $P$-waves.

According to the estimates in [5], sources of acoustic signals occurring in sedimentary rocks at the frequencies from first hundreds of $\mathrm{Hz}$ to the first tens of $\mathrm{kHz}$ are located at the distances up to the first tens of meters from the hydrophone. Taking into account this fact, sedimentary rock layer thickness and the distance between electrodes for electric signal recording and their depth in soil (10 and $1 \mathrm{~m}$, respectively), we can consider that the observed seismoacoustic and seismoelectric signals are generated in near-surface sedimentary rocks.

From January 2016 to March 2020, during the measuring system operation, six earthquakes with $M_{w}>6.5$ occurred in Kamchatka region. Their parameters, which were taken from NEIC catalogue (https://earthquake.usgs.gov/earthquakes/search/), are listed in the table. It also shows epicentral and hypocentral distances to our site and the difference of longitudinal and transversal wave arrival to seismic "Karymshina" site. Location of earthquake epicenters and their numbers (see the table 1) are illustrated in Fig. 1.

Table 1. Parameters of earthquakes during which seismoacoustic and seismoelectric signals were analyzed. $R, D$ are epicentral and hypocentral distances; $(S-P)$ is the difference of longitudinal and transversal wave arrival times.

\begin{tabular}{|c|c|c|c|c|c|c|c|c|c|}
\hline \multirow{2}{*}{ No. } & \multicolumn{2}{|c|}{ Earthquake } & \multicolumn{2}{|c|}{$\begin{array}{l}\text { Epicenter } \\
\text { coordinates }\end{array}$} & \multirow{2}{*}{$\begin{array}{l}\text { Depth, } \\
\text { km }\end{array}$} & \multirow{2}{*}{$\begin{array}{l}\text { Magni- } \\
\text { tude } \\
\text { (mww) }\end{array}$} & \multirow{2}{*}{$\begin{array}{l}R, \\
\mathrm{~km}\end{array}$} & \multirow{2}{*}{$\begin{array}{c}D, \\
\mathrm{~km}\end{array}$} & \multirow{2}{*}{$\begin{array}{c}S-P, \\
\mathrm{~s}\end{array}$} \\
\hline & $\begin{array}{l}\text { Date, } \\
\text { UTC }\end{array}$ & $\begin{array}{l}\text { Time, } \\
\text { UTC }\end{array}$ & Lat. $^{\circ} \mathrm{N}$ & Long. ${ }^{\circ} \mathrm{E}$ & & & & & \\
\hline 1 & $2016-01-30$ & $03: 25: 12$ & 53.978 & 158.546 & 177 & 7.2 & 131.1 & 220.2 & 22.7 \\
\hline 2 & $2017-03-29$ & 04:09:24 & 56.940 & 162.786 & 17.0 & 6.6 & 544.8 & 545.0 & 58.2 \\
\hline 3 & $2017-07-17$ & $23: 34: 13$ & 54.443 & 168.857 & 10.0 & 7.7 & 727.8 & 727.9 & - \\
\hline 4 & 2018-10-13 & $11: 10: 22$ & 52.855 & 153.243 & 461.0 & 6.7 & 327.8 & 565.7 & 55.1 \\
\hline 5 & $2018-12-20$ & $17: 01: 55$ & 55.100 & 164.699 & 16.6 & 7.3 & 497.5 & 497.8 & 47.8 \\
\hline 6 & $2020-03-25$ & $02: 49: 21$ & 48.964 & 157.696 & 57.8 & 7.5 & 430.2 & 434.0 & 43.8 \\
\hline
\end{tabular}

\section{Results and discussion}

Due to the small amplitude of acoustic and electric signals (compared to noise) and absence of the possibility of their qualitative analysis, seismoacoustic and seismoelectric responses of sedimentary rocks were not considered for earthquakes No. 2, 3, 4. Fig. 1-4 show the spectrograms of acoustic and electric signals recorded during seismic wave propagation from earthquakes No. 1, 5, 6 (table 1). As it is clear from Fig. 2a, propagation of $P$-wave from earthquake No. 1 was accompanied by acoustic energy emission in three frequency clusters. 
Besides the low-frequency cluster of about up to $100 \mathrm{~Hz}$, there are two clusters at the frequencies of about $0.1-1 \mathrm{kHz}$ and $1-11 \mathrm{kHz}$. They indicate transformation of low-frequency energy of elastic seismic waves into significantly higher-frequency energy of acoustic emission of sedimentary rocks located near the hydrophone. According to the signal spectrograms (Fig. 2b,c), electric energy was emitted at the frequencies up to $15-20 \mathrm{~Hz}$ during $P$ - and $S$ waves. The emission energy was greater in $E-W$ channel.

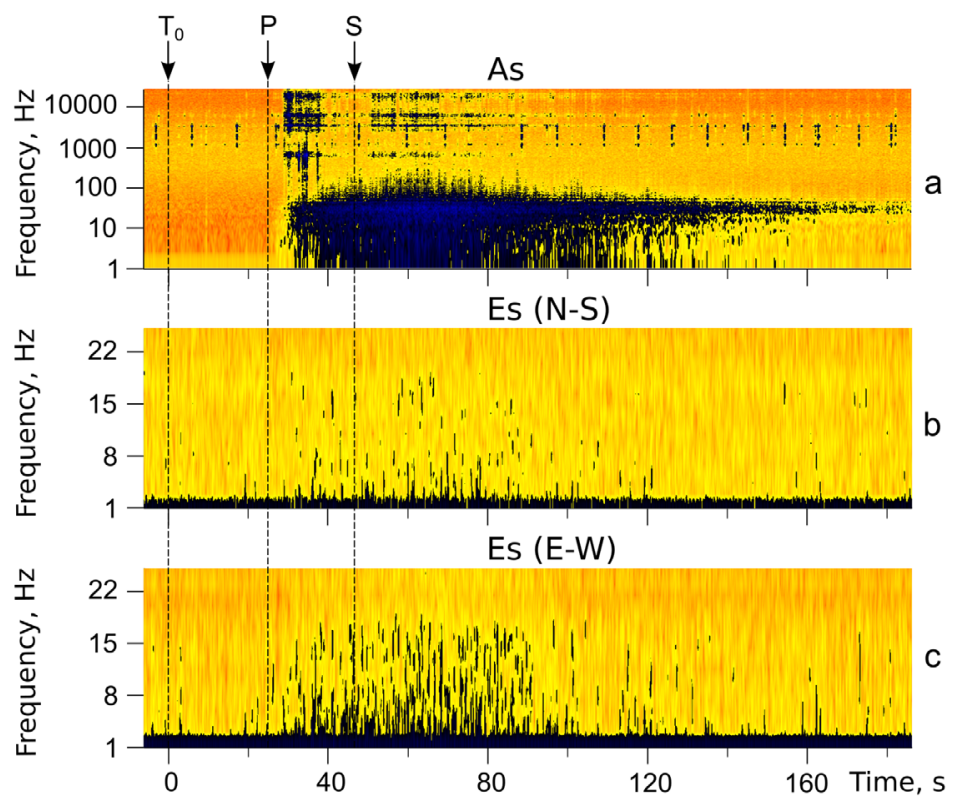

Figure 2. Spectrograms of acoustic (As) and electric Es (N-S), Es (E-W) signals recorded during seismic wave propagation from earthquake No. 1 (Fig. 1, table 1). Arrows indicate the times of earthquake T0 and longitudinal $(P)$ and transversal $(S)$ wave arrival to the seismic "Karymshina" station.

Fig. 3 illustrates the results of analysis of acoustic and electric signals recorded during seismic wave propagation from earthquake No. 5. In contrast to earthquake No. 1 (Fig. 2a), there are no kilohertz acoustic clusters during $P$-wave (Fig. 3a). Electric response of sedimentary rocks is observed at the frequencies up to $20-22 \mathrm{~Hz}$ during the propagation of both types of waves and only in $N-S$ channel (Fig. 3b,c). Moreover, response intensity is higher during $P$-wave. A strong short-term signal in the time interval $83.61-83.75 \mathrm{~s}$ (Fig. 3b,c) is caused by a group of strong atmospherics according to electromagnetic observations of "Karymshina" site.

Fig. 4 shows the results of analysis of acoustic and electric signals recorded during seismic wave propagation from earthquake No. 6. According to Fig. $4 \mathrm{a}$, during the $P$-wave, besides the low-frequency acoustic cluster of up to $100 \mathrm{~Hz}$, higher-frequency cluster is observed at the frequencies of about $0.1-1 \mathrm{kHz}$, but there is no cluster at the frequencies of 1-11 kHz just like during earthquake No. 1. Sedimentary rock electric response manifests at the frequencies up to $20-22 \mathrm{~Hz}$ almost with the same intensity at both channels and only during the $S$-wave (Fig. 4b,c).

Fig. 5 presents the behavior of displacement vector module $|S|$, displacement velocity vector module $|V|$ and spectral density of displacement velocity vector module $S_{x}$ of soil during $P$-wave from earthquakes No. 1, 5, 6. When comparing $|S|$ values (Fig. 5a,d,g), it 


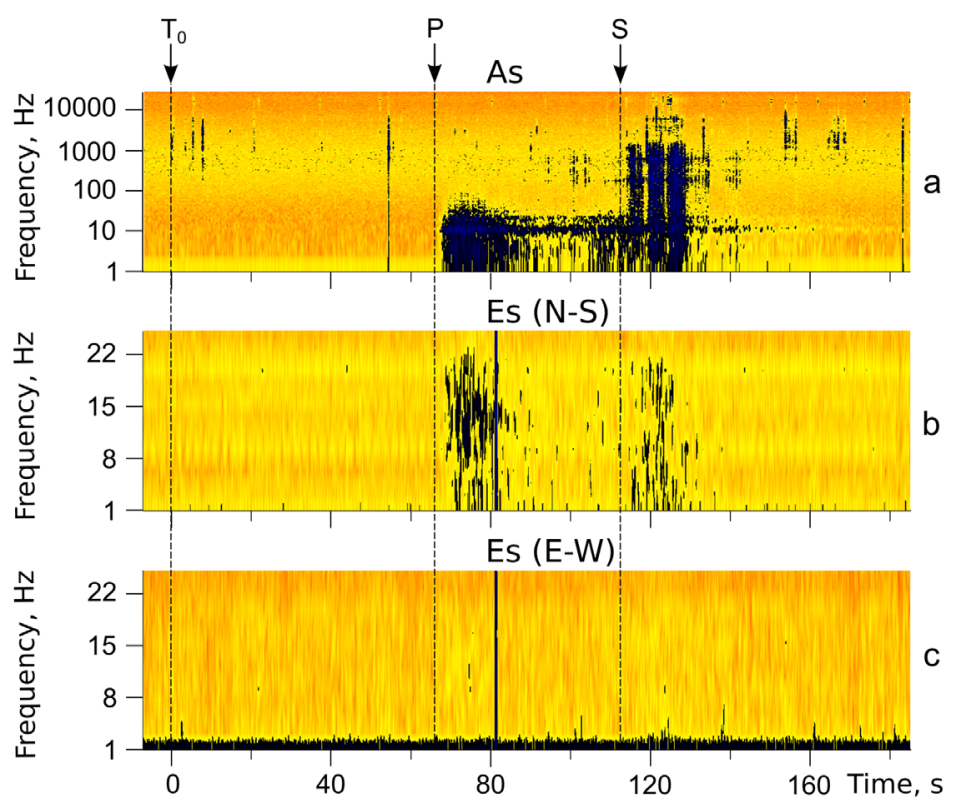

Figure 3. Spectrograms of acoustic (As) and electric Es (N-S), Es (E-W) signals recorded during seismic wave propagation from earthquake No. 5 (Fig. 1, table 1). Arrows are the same as in Fig. 2.

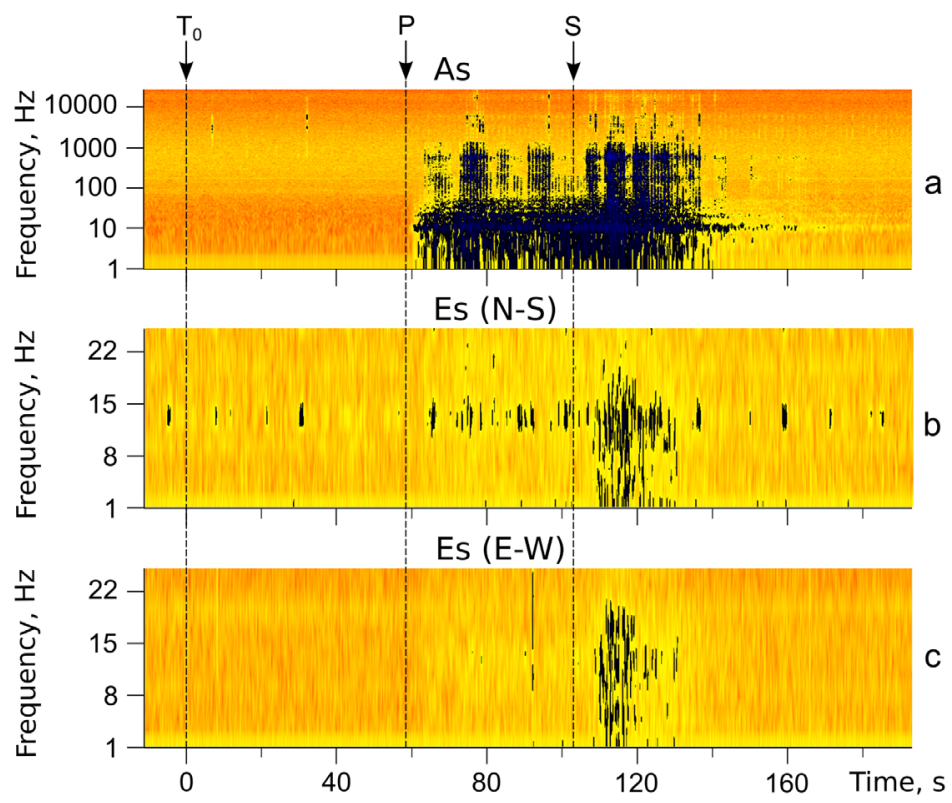

Figure 4. Spectrograms of acoustic (As) and electric Es (N-S), Es (E-W) signals recorded during seismic waves propagation from earthquake No 6 (Fig. 1, table 1). Arrows are the same as in Fig. 2. 
is clear that the greatest displacement of soil is observed during earthquake No. 1. Average $|S|$ values during these earthquakes differ by not more than 3 times. There is significant difference in $|V|$ behavior (Fig. 5b,e,h). As it is clear from Fig. 5b, during earthquake No. 1 there are well defined high-amplitude $|V|$ variations the frequency of which is $3.0 \mathrm{~Hz}$ (Fig. 5c). There are no such $|V|$ variations during earthquakes No. 5 (Fig. 5e,f), but they are evident during earthquake No. 6 within the time interval of 0-20 s (Fig. 5h, selection). Behavior of $|V|$ and its spectral density $S_{x}$ during this time interval are illustrated in detail in Fig. 6 . It is clear that there are $|V|$ variations at the frequency of $2.3 \mathrm{~Hz}$ (Fig. 6b) during earthquake No. 6 (Fig. 6a).

Thus, despite of the close magnitudes for earthquakes No. 1, 5, 6, sedimentary rock acoustic response manifests in different ways. It is likely to be associated with different distances to earthquake hypocenters $D$. Indeed, the greatest, still evident frequency of this response during earthquakes No. 1,6 and 5 reaches $11 \mathrm{kHz}, 1 \mathrm{kHz}$ and $100 \mathrm{~Hz}$, respectively, and $D$ increases as 220, 434 and $498 \mathrm{~km}$. Evidently, seismic wave attenuates that is confirmed by $|S|$ and $|V|$ amplitude decrease during the $P$-wave from these earthquakes (Fig. 5a,g,d and $\mathrm{b}, \mathrm{h}, \mathrm{e}$, respectively). Small amplitude of acoustic and electric signals during earthquakes No. $2,3,4$, which was mentioned above, can be explained by the dependence of manifestation of sedimentary rock acoustic and electric responses on earthquake magnitude $[3,4]$ and the longest distance to the hypocenter in case of earthquake No. 3 .

Occurrence of sedimentary rock high-frequency acoustic response (Fig. 2a, 4a) may be associated with the variations of soil displacement velocity vector module $|V|$, which were observed during the P-wave from earthquakes No. 1, 6 (Fig. 5b, 6a). As it was said above, these variations were at the frequency of 3.0 and $2.3 \mathrm{~Hz}$, respectively. They were absent during earthquake No. 5 when there was no such a response. We think that the difference of these frequencies indicates natural origin of the variations which can be associated with relative slippages of sedimentary rock fragments during deformation intensification. During deformation and acoustic observations at "Karymshina" site [6] it was discovered that acoustic signals in kilohertz frequency range are generated in the result of rock fragment adhesion loss and slippages.

Electric response of sedimentary rocks as acoustic one also manifested in different ways. It is observed in both measuring channels (Fig. 2b,c; 4b,c) or only in one (Fig. 3b,c). This response is clear during $P$ - and $S$-wave (Fig. 2b,c; 3b) or during only $S$-wave (Fig. 4b,c). In $[3,4]$ the dependence of rock electric response on earthquake amplitude was discovered. Its intensity in measuring channels (response anisotropy) is associated with location of earthquake epicenter relatively the site [3,4]. Evidently, the efficiency of seismoelectric transformation depends on sedimentary rock structure and texture. According to [7], it is also mainly determined by their stress-strain state which varies with time. Thus, electric response manifestation in sedimentary rocks could be affected by different time of occurrence of earthquakes No. 1, 5, 6 (table 1).

To find the statistical significance of the obtained results, we need to continue the acoustic and electric observations during other strong earthquakes of different magnitude and with different location of hypocenters relatively the site. 

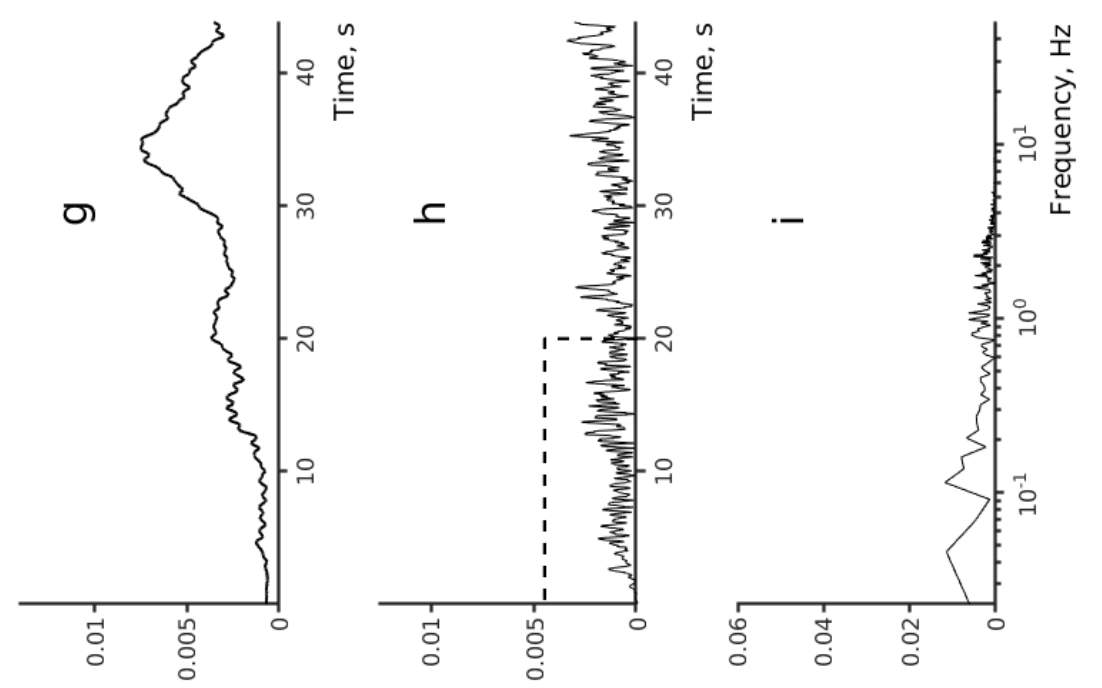

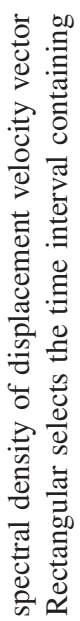
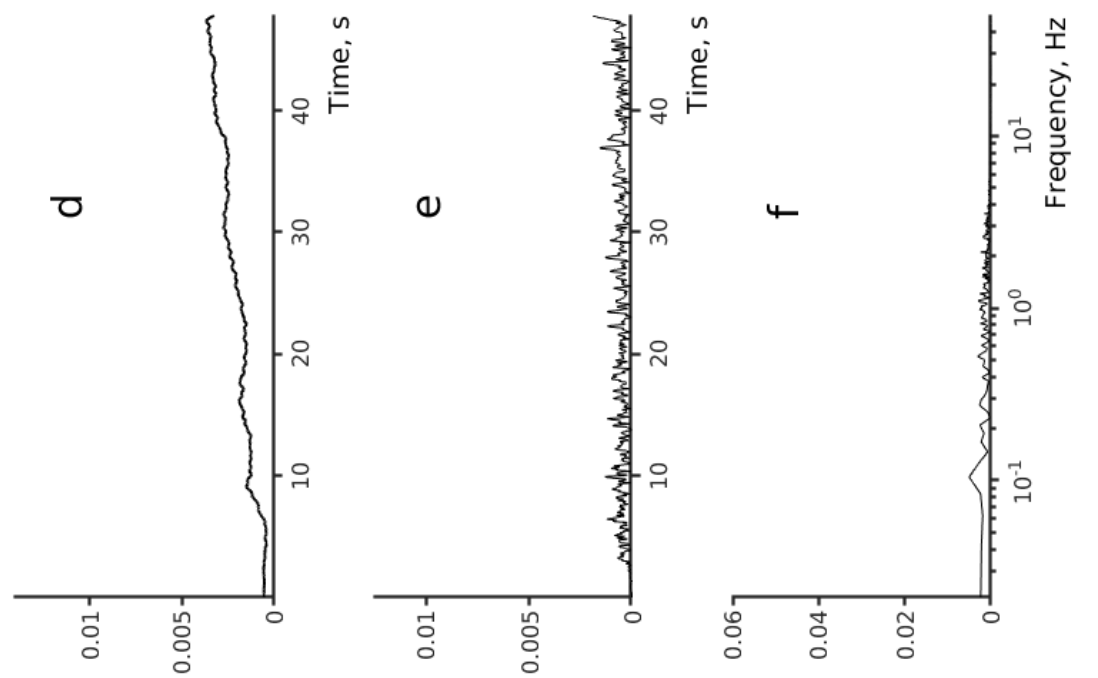

产

a.

eे

$\geq$

$\frac{0}{3}$

\&

安

要

त्र

율

苛

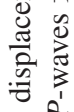

on
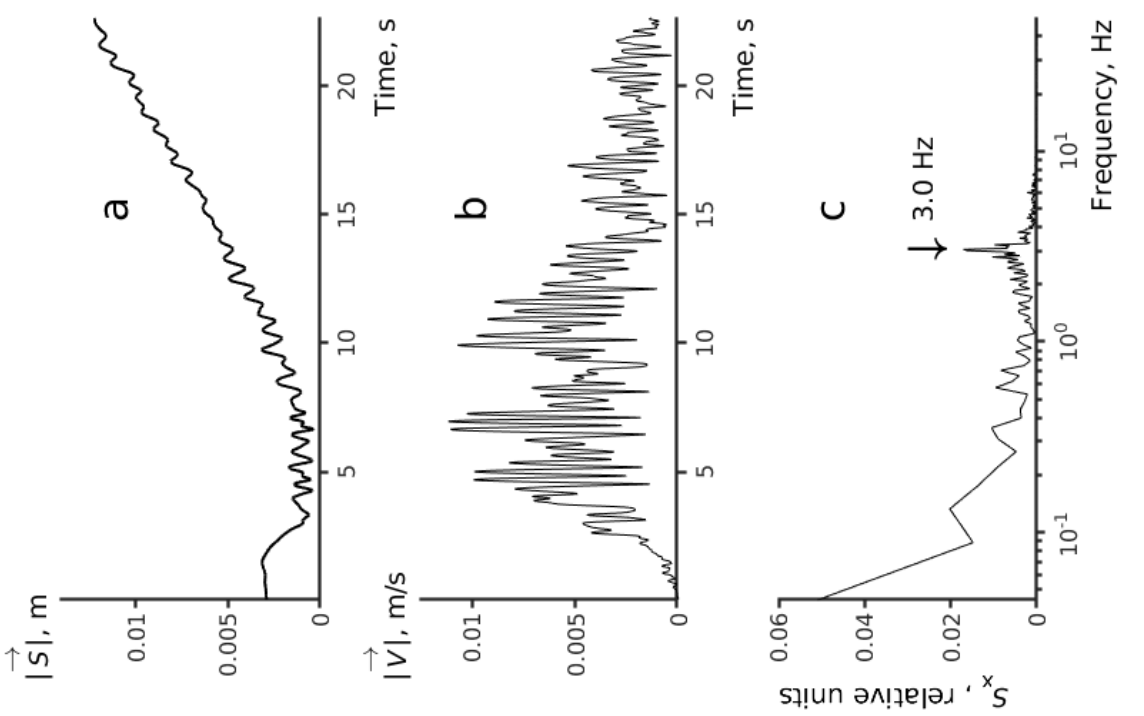

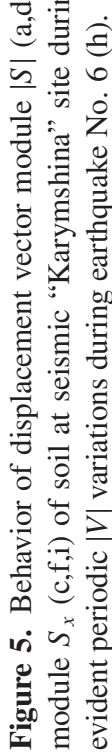



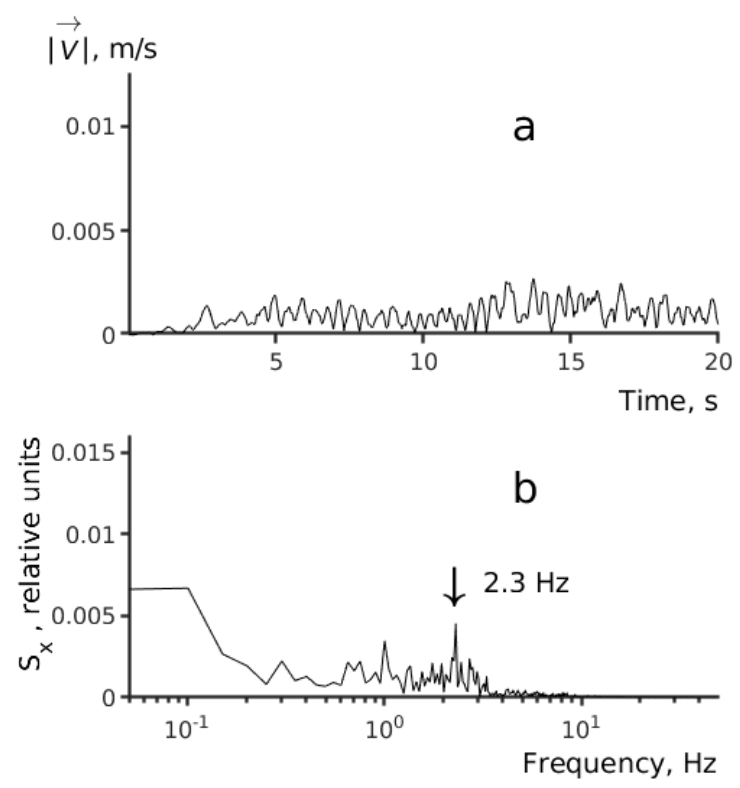

Figure 6. Behavior of displacement velocity vector module $|V|$ (a) and its spectral density $S_{x}$ (b) during the time interval selected by the rectangular in Fig. $5 \mathrm{~h}$.

\section{Conclusions}

We have suggested a new method for joint investigation of near-surface sedimentary rock acoustic and electric responses occurring during deformations by seismic waves from earthquakes. The method includes simultaneous recording of these responses and comparison of the features of their manifestation with the behavior of three components of soil displacement and displacement velocity during longitudinal and transversal wave propagation from strong earthquakes at observation site region.

Applying this method we considered the manifestations of near-surface sedimentary rock acoustic and electric responses during deformations by seismic waves from six earthquakes with the magnitudes of $M_{w}=6.6-7.7$ and the distances of 131-728 km from epicenters in Kamchatka region. We have confirmed the earlier discovered dependence of intensity and the character of response manifestation on earthquake magnitude and the distance to its source. It was detected that acoustic response occurrence in kilohertz frequency range agrees well with the behavior of soil displacement velocity vector module and its spectrum.

The obtained results are interesting for the investigation of mechanic-acoustic and mechanic-electric transformations appearing during tectono-seismic deformation of widely spread near-surface sedimentary rocks.

The authors appreciate Kamchatka Branch of FRC GS RAS for the data on soil displacement and displacement velocity at "Karymshina" site during the earthquakes under consideration.

\section{References}

[1] M.A. Sadovskiy, L.G. Bolhovitinov, V.F. Pisarenko, Deformation of the geophysical environment and seismic process (Moscow, Nauka, 1987) 
[2] R.M. Garrels, F.T. Mackenzie, textitEvolution of sedimentary rocks (W.W. Norton and Company, Inc., New York, 1971)

[3] P.V. Muratov, O.P. Rulenko, Yu.V. Marapulets, A.A. Solodchuk, Bulletin KRASEC. Physical \& Mathematical Sciences, 5(25), 62-73 (2018)

[4] P.V. Muratov, O.P. Rulenko, Yu.V. Marapulets, E3S Web of Conferences, 127 (02015), (2019)

[5] Yu.V. Marapulets, B.M. Shevtsov, Mesoscale acoustic emission (Vladivostok, Dal'nauka, 2012)

[6] G.I. Dolgikh, A.V.Kuptsov, I.A. Larionov et. al, Doklady Earth Science, 413(1), 96-100 (2007)

[7] N.I. Migunov, Izvestiya. Physics of the Solid Earth, 9, 20-28 (1984) 